\title{
Prevalence of adrenal insufficiency among patients with euvolemic hyponatremia
}

\author{
Amit Kumar ${ }^{1}$, Maria Ghosh ${ }^{2}$ and Jubbin Jagan Jacob $\mathbb{1}^{3}$ \\ ${ }^{1}$ Department of Medicine, Christian Medical College and Hospital, Ludhiana, Punjab, India \\ ${ }^{2}$ Department of Biochemistry, Christian Medical College and Hospital, Ludhiana, Punjab, India \\ ${ }^{3}$ Department of Endocrinology, Christian Medical College and Hospital, Ludhiana, Punjab, India
}

Correspondence should be addressed to J J Jacob: jubbin.jacob@cmcludhiana.in

\begin{abstract}
Background: The diagnosis of syndrome of inappropriate anti-diuresis requires the exclusion of secondary adrenal insufficiency ( $\mathrm{Al}$ ) among patients with euvolemic hyponatremia (EuVHNa). Studies have suggested that about $2.7-3.8 \%$ of unselected patients presenting to the emergency room with EuVHNa have undiagnosed $\mathrm{Al}$ and it is as high as $15 \%$ among patients admitted to specialized units for evaluation of hyponatremia.

Objective: To study the prevalence of Al among in-patients with EuVHNa in a general medical ward setting.

Methods: This was a prospective, single-center observational study conducted among general medical in-patients with EuVHNa, defined as patients with a serum sodium $<135 \mathrm{mmol} / \mathrm{L}$, clinical euvolemia and urine spot sodium $>30 \mathrm{mmol} / \mathrm{L}$. Additionally, patients with recent vomiting, current renal failure, diuretic use and those with uncontrolled hyperglycemia were excluded. Adrenal functions were assessed by a modified adrenocorticotropic hormone (ACTH) stimulation test called the Acton Prolongatum ${ }^{\mathrm{TM}}$ stimulation test (APST). A cut-off cortisol value of $<18 \mathrm{mg} / \mathrm{dL}$ after $60 \mathrm{~min}$ of ACTH injection was used to diagnose Al.

Results: One hundred forty-one patients were included and underwent an APST. APST suggested 20/141 (14.2\%) had undiagnosed Al. The commonest cause of Al (9/20) was secondary Al because of the use of steroids including inhaled steroids and indigenous medicines contaminated with steroids. In 5 (3.5\%) patients hypopituitarism was newly diagnosed. Despite primary AI (PAI) not commonly presenting as EuVHNa, 2/20 patients had PAI.

Conclusions: Al is much commoner in our country, among in-patients with EuVHNa primarily driven by exogenous steroid use and undiagnosed hypopituitarism.
\end{abstract}

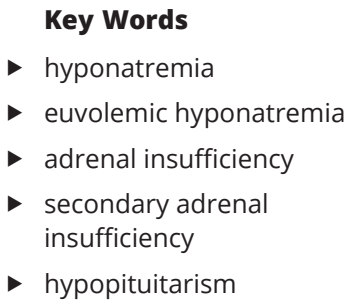

Endocrine Connections (2021) 10, 1623-1631

\section{Introduction}

Two percent of community-dwelling adults in America have hyponatremia. These rates are more than double among adults over the age of 71 years (1). In hospitalized patients, the prevalence of hyponatremia is between 15 and $20 \%$ and it remains the commonest electrolyte disturbance seen among them (2). Hyponatremia leads to increases in morbidity, length of hospitalization and mortality among those admitted in hospital $(3,4,5)$.

A large majority of in-patients with hyponatremia have osmotically inappropriate anti-diuretic hormone (ADH) secretion (6). This makes the use of direct measurements of $\mathrm{ADH}$ or co-secreted proteins like co-peptin or other https://ec.bioscientifica.com https://doi.org/10.1530/EC-21-0500 (c) 2021 The authors Published by Bioscientifica Ltd
This work is licensed under a Creative Commons Attribution-NonCommercial-NoDerivatives 4.0 elnternationab bicense ifica.com at 04/26/2023 11:23:41AM 
indirect markers like urine osmolality and solute-free water clearance not of much clinical value in management of in-patient hyponatremia except in rare cases of primary polydipsia or inappropriate in hospital fluid management (7).

Currently, clinicians still use the diagnostic scheme first proposed by Schrier and colleagues almost 30 years back for classifying hyponatremia based on volume status (8). Despite decrease (in hyponatremia with dehydration), near-normal (euvolemic hyponatremia) or increase (edematous hyponatremia) in total body sodium among patients with hyponatremia, all three conditions are associated with a relative excess of water (6). This selective water retention in all three conditions is mediated by osmotically inappropriate release of $\mathrm{ADH}$ from the posterior pituitary. This is one reason why hyponatremia should be essentially considered a hormonal disorder of water metabolism and should involve active involvement of endocrine specialists.

Most hospitalized patients with hyponatremia do not get appropriately investigated even in tertiary care hospitals around the world $(9,10,11,12)$. There is some evidence that this lack of proper investigations maybe contributing to the mortality that is seen with severe hyponatremia (13). A retrospective study from the United Kingdom suggested that patients who were reviewed by the endocrinology service in the hospital were 16 times more likely to have a more complete laboratory workup than those not referred to endocrinology services (14).

The syndrome of inappropriate anti-diuresis (SIAD) is the principal cause of euvolemic hyponatremia (EuVHNa). Although SIAD has a specific diagnostic criteria, it remains a diagnosis of exclusion and needs the absence of secondary adrenal insufficiency (AI) and hypothyroidism as an essential criterion for the diagnosis. Evaluation of the hypothalamic-pituitary-adrenal (HPA) axis is, however, missed in over two-thirds of the patients labeled as having SIAD (14).

Clear estimates of the contribution of secondary AI to EuVHNa are hard to come by. We could locate only one previous study that prospectively evaluated the HPA axis in-patients with EuVHNa. In a large single-center study done from Beaumont Hospital in Ireland, unsuspected AI was noted in $3.8 \%$ of patients and was identified as SIAD. A little less than half of them (1.5\%) had undiagnosed pituitary disease (15).

Secondary AI among patients with EuVHNa is likely to be higher in India because of two reasons. The first reason being the significant number of patients prescribed inappropriate unlabeled glucocorticoids either as part of local remedies or as injectables by unqualified medical practitioners (16). The second reason being an increased prevalence of undiagnosed hypopituitarism among older menopausal women due to post-partum pituitary necrosis (Sheehan's syndrome) reflecting poor obstetric care received decades earlier (17).

With this background, we planned this study to prospectively ascertain the prevalence of AI among in-patients admitted to medical wards with EuVHNa.

\section{Materials and methods}

\section{Study design and study location}

This was a prospective observational study conducted in the Department of Medicine at Christian Medical College and Hospital in the North Indian city of Ludhiana from 15 December 2017 to 14 December 2018. The hospital is a tertiary care teaching hospital with a total of 720 beds which includes 120 beds for general medicine.

\section{Patient selection}

All adult patients admitted into the general medical wards consisting of 120 beds over a period of 1 year between 15 December 2017 and 14 December 2018 were evaluated for hyponatremia (serum sodium $<135 \mathrm{mmol} / \mathrm{L}$ ). Among them, patients with EuVHNa who met the inclusion criteria and provided consent were further evaluated with the determination of thyroid functions tests and an Acton Prolongatum ${ }^{\circledast}$ (adrenocorticotropic hormone(1-34) (ACTH(1-34)) stimulation test (APST).

\section{Inclusion and exclusion criteria}

Adult patients ( $\geq 18$ years) with EuVHNa who provided consent were included. Patients were considered to have EuVHNa if they met the following three criteria: (i) Serum sodium levels < $135 \mathrm{mmol} / \mathrm{L}$; (ii) No clinical evidence of dehydration (sunken eyes, loss of skin turgor, dry oral mucosa and hypotension) or evidence of fluid excess (presacral or pedal edema or ascites) and (iii) Urine spot sodium values $>30 \mathrm{mmol} / \mathrm{L}$.

Some causes of hyponatremia could potentially have urine spot sodium levels $>30 \mathrm{mmol} / \mathrm{L}$ despite not being euvolemic. These were excluded as far as possible. Exclusion criteria included patients with $>4$ episodes of vomiting over the past $24 \mathrm{~h}$ prior to assessment, patients on diuretics within the past $72 \mathrm{~h}$ and patients with renal failure

This work is licensed under a Creative Commons Attribution-NonCommercial-NoDerivatives 4.0 International License.ifica, com at $04 / 26 / 2023$ 11:23:41AM 
(eGFR $<30 \mathrm{~mL} / \mathrm{min} / 1.7 \mathrm{~m}^{2}$ ). Unwell patients requiring transfer or transferred in from high dependency unit or intensive care unit were also excluded. All patients were evaluated for inclusion by a single researcher (first author). Additionally, patients with possible pseudohyponatremia defined as serum triglyceride levels $>500 \mathrm{mg} / \mathrm{dL}$ (5.65 mmol/L) or total protein levels $>10 \mathrm{mg} / \mathrm{dL}(100 \mathrm{~g} / \mathrm{L})$ were excluded. Patients receiving mannitol infusions were excluded. Other exclusion criteria included patients with blood glucose values $>400 \mathrm{mg} / \mathrm{dL}(22.2 \mathrm{mmol} / \mathrm{L})$, those who received oral or i.v. steroids within the last 6 months from screening, those with established AI and those who previously have had allergic reaction to Acton Prolongatum $^{\mathrm{TM}}$ or Synacthen ${ }^{\mathrm{TM}}$.

\section{Ethical approval and registration of study protocol}

The study protocol was approved by the Institutional Ethics Committee of Christian Medical College and Hospital prior to any study related activities. The protocol was registered with the Baba Farid University of Health Sciences (http://www.bfuhs.ac.in/examination/ PlanOfThesis/Topic20172020.pdf) prospectively as part of Doctor of Medicine (MD) thesis in general medicine for the first author and the principal investigator of the study under supervision of the other two authors. All patients only underwent study procedures once they provided an informed consent in a language comfortable to them (English, Hindi and Punjabi). Consent from a legally acceptable representative was sought if the subject was unable to provide consent.

\section{Biochemical methods}

Quantitative estimation of sodium in serum was performed using indirect ion selective electrodes (ISE). The samples received for serum sodium estimation were centrifuged immediately to separate the serum. Grossly lipemic serum was rejected. The measuring range for serum sodium using indirect ISE was $80-180 \mathrm{mmol} / \mathrm{L}$. Precision and repeatability were checked daily by running quality control samples in both low to normal and high ranges of sodium. For repeatability testing, the coefficient of variation $(\mathrm{CV}) \%$ for low to normal and high levels was 0.3 and $0.2 \%$, respectively. For precision testing, the CV\% for low to normal and high sodium levels was 1.1 and $0.4 \mathrm{mmol} / \mathrm{L}$, respectively.

Quantitative determination of serum cortisol was performed using Elecsys Cortisol II kit on Cobas e411/601 fully automated analyzer from Roche ${ }^{\mathrm{TM}}$. The Elecsys
Cortisol II assay makes use of a competition test principle using a MAB which is specifically directed against cortisol. Endogenous cortisol which has been liberated from binding proteins with danazol competes with exogenous cortisol derivative in the test which has been labeled with ruthenium complex for the binding sites on the biotinylated antibody. Measuring range of the test was $0.054-63.4 \mu \mathrm{g} / \mathrm{dL}(1.5-1750 \mathrm{mmol} / \mathrm{L})$. Values below the limit of detection were reported as $<0.054 \mu \mathrm{g} / \mathrm{dL}$ $(<1.5 \mathrm{mmol} / \mathrm{L})$ and values above the measuring range $>63.4 \mu \mathrm{g} / \mathrm{dL}$ or up to $634 \mu \mathrm{g} / \mathrm{dL}(17,500 \mathrm{mmol} / \mathrm{L})$ after 10-fold dilution of samples.

The values of free $\mathrm{T}_{4}\left(\mathrm{FT}_{4}\right)$ and $\mathrm{TSH}$ in human serum were determined using the electrochemiluminescence immunoassay on Cobas e411/601 immunoassay analyzer. These tests were performed on undiluted serum samples collected in standard sampling tubes without additives. For $\mathrm{FT}_{4}$ estimation, the measuring range was $0.3-100 \mathrm{pmol} / \mathrm{L}$ and for TSH the measuring range was 0.005-100 mIU/L. The analytical sensitivity and total precision values for $\mathrm{FT}_{4}$ were $0.30 \mathrm{pmol} / \mathrm{L}$ and $2.7 \%$ and for TSH assays, they were $0.005 \mathrm{mIU} / \mathrm{L}$ and $2.2 \%$, respectively. In adult patients, the normal reference range for FT4 was 12-22 pmol/L and for TSH it was $0.270-4.20 \mathrm{mIU} / \mathrm{L}$.

\section{Acton Prolongatum ${ }^{\mathrm{TM}}(\mathrm{ACTH}(1-34))$ stimulation test}

A guideline from the Endocrine Society recommends the use of a standard (250 $\mu \mathrm{g})$ dose of cosyntropin (tetracosactide hexacetate) as the stimulus of choice to perform stimulation testing of the HPA axis $(18,19)$. Synacthen ${ }^{\mathrm{TM}}$ (brand of cosyntropin) has not been officially marketed in India for over a decade. The drug is currently available from select importers of the drug at high costs with poor reliability of supplies. In 2013, Gundgurthi and colleagues first suggested using the porcine sequence ACTH(1-34) easily available in India from Ferring Pharmaceuticals as a treatment of infantile spasms. The product is marketed in India with the brand name of Acton Prolongatum $^{\mathrm{TM}}$ and is available as $60 \mathrm{IU} / \mathrm{mL}$ multidose vial of $5 \mathrm{~mL}$ each. They used $25 \mathrm{IU}$ of this preparation intramuscularly and for the first time established its effectiveness as an adequate stimulus to check the HPA axis. The post-injection sample was drawn at $60 \mathrm{~min}$. This test is also referred to as the APST (20).

We followed a similar protocol for the APST in our study. Subjects had a basal sample drawn following which $25 \mathrm{IU}(\sim 0.4 \mathrm{~mL})$ of Acton Prolongatum ${ }^{\circledast}$ was drawn using an insulin syringe ( 16 units with a $40 \mathrm{IU} / \mathrm{mL}$ syringe which is commonly available in India). This was administered over

This work is licensed under a Creative Commons Attribution-NonCommercial-NoDerivatives 4.0 Internationad dicense ifica. com at 04/26/2023 11:23:41AM 
the deltoid region as an i.m. injection. The post-injection sample was drawn at $60 \mathrm{~min}$.

Standard cut-offs were used to define AI at $60 \mathrm{~min}$ post-APST. Patients with $60 \mathrm{~min}$ post-APST values less than $18 \mu \mathrm{g} / \mathrm{dL}(500 \mathrm{nmol} / \mathrm{L})$ were considered to have AI as with the standard cut-offs for short Synacthen test (SST) (18). Patients with suboptimal cortisol responses were immediately treated with i.v. hydrocortisone after discussion with treating consultant. All APST tests were done in the ward during hospitalization. Further evaluations for patients with AI were performed by the treating medicine team, and the endocrinology team was only involved when specifically consulted and repeat testing was done in an outpatient setting if indicated to decide on long-term steroid replacements.

Recently, two further papers from India have suggested a good agreement between the standard SST and APST and highlighted the significant cost savings $(21,22)$.

\section{Sample size calculations and statistical methods used}

Using the prevalence of EuVHNa of 50.7\% among patients admitted with hyponatremia to a similar tertiary hospital in India, we calculated the sample size of at least 140 patients using the formula $n=Z \alpha^{2} \times \mathrm{P} \times(1-\mathrm{P}) / \mathrm{d}^{2}$ were $\mathrm{Z} \alpha^{2}=1.96$, the standard normal deviate and $\mathrm{P}=50.7 \%$ and $\mathrm{d}=8 \%$ as allowable error (23).

All obtained data were entered in MS Excel sheet and summarized using distribution and descriptive statistics. Chi-square test was used to find association between categorical variables and Fisher's exact test was used to find the significant difference of continuous variables.

\section{Results}

During the study period, 4007 patients were admitted to the medical wards. Seven hundred eighty-three patients had biochemical hyponatremia at admission or on biochemistry done within $24 \mathrm{~h}$ of admission. One hundred forty-one patients with EuVHNa met the inclusion and exclusion criteria and were consented for the study. All of them underwent an APST. Based on the previously determined cut-off of patients with post-APST $(60 \mathrm{~min})$ values of $<18 \mu \mathrm{g} / \mathrm{dL}$ (500 nmol/L), 20/141 (14.2\%) patients had AI.

Baseline data among those who had AI and among those who did not have AI are given in Table 1.

More clinical details of the 20 patients diagnosed with AI including possible etiologies are given in Table 2. Undocumented steroid use or unscrupulous addition of steroids to indigenous medications was the cause for secondary $\mathrm{AI}$ in 5/20 (25 or 3.5\% among all patients with EuVHNa) patients. The other causes included undiagnosed hypopituitarism $5 / 20$ (25 or $3.5 \%$ among all patient with EuVHNa) which included three patients with postpartum pituitary necrosis (Sheehan's syndrome) and two patients with possible lymphocytic hypophysitis. We were surprised to note that the use of high-dose-inhaled steroids caused significant suppression of the HPA axis to cause significant hyponatremia in $4 / 20$ patients (20 or $2.8 \%$

Table 1 Baseline characteristics among patients with Al and among those without Al.

\begin{tabular}{|c|c|c|c|}
\hline & Patients with Al $(n=20)$ & Patients without Al $(n=121)$ & $P$-value \\
\hline Age in years (mean \pm S.D.) & $55 \pm 12.02$ & $58.31 \pm 15.57$ & 0.37 \\
\hline Male gender $(\%)$ & 55 & 50.4 & 0.42 \\
\hline Weight in kg (mean \pm s.D.) & $64.2 \pm 8.45$ & $64.95 \pm 13.35$ & 0.81 \\
\hline eGFR in mL/min/1.73 m² (mean \pm s.D.) & $116.76 \pm 74.88$ & $102.46 \pm 44.79$ & 0.24 \\
\hline Serum sodium in mmol/L (mean \pm S.D.) & $126.05 \pm 5.86$ & $125.13 \pm 7.67$ & 0.61 \\
\hline \multicolumn{4}{|l|}{ Biochemical severity } \\
\hline 1. Mild (\%) & $6(30.0)$ & $38(31.4)$ & 0.89 \\
\hline 2. Moderate (\%) & $7(35.0)$ & $47(38.8)$ & \\
\hline 3. Profound (\%) & $7(35.0)$ & $36(29.8)$ & \\
\hline TSH levels in mIU/L (mean \pm s.D.) & $8.69 \pm 21.09$ & $3.31 \pm 4.55$ & 0.01 \\
\hline Free $\mathrm{T}_{4}$ in pmol/L (mean \pm S.D.) & $17.54 \pm 9.65$ & $17.42 \pm 5.71$ & 0.94 \\
\hline Basal cortisol values in $\mu \mathrm{g} / \mathrm{dL}$ (mean \pm s.D.) & $5.58 \pm 3.80$ & $15.78 \pm 8.70$ & 0.00 \\
\hline Post-APST - 60 min cortisol in $\mu \mathrm{g} / \mathrm{dL}$ (mean \pm s.D.) & $13.04 \pm 3.20$ & $28.32 \pm 10.74$ & 0.00 \\
\hline
\end{tabular}

Mild hyponatremia (serum sodium between 130 and134 mmol/L), moderate (serum sodium between 125 and 129 mmol/L) and profound (serum sodium $<125 \mathrm{mmol} / \mathrm{L})$.

APST, Acton Prolongatum ${ }^{\mathrm{TM}}$ stimulation test; Al, adrenal insufficiency; eGFR, estimated glomerular filtration rate by modification in diet in renal disease formula; TSH, thyroid-stimulating hormone.

https://ec.bioscientifica.com https://doi.org/10.1530/EC-21-0500 (c) 2021 The authors Published by Bioscientifica Ltd

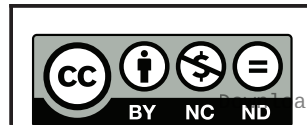

This work is licensed under a Creative Commons Attribution-NonCommercial-NoDerivatives 4.0 internationad ficense ifica . com at $04 / 26 / 2023$ 11:23:41AM 


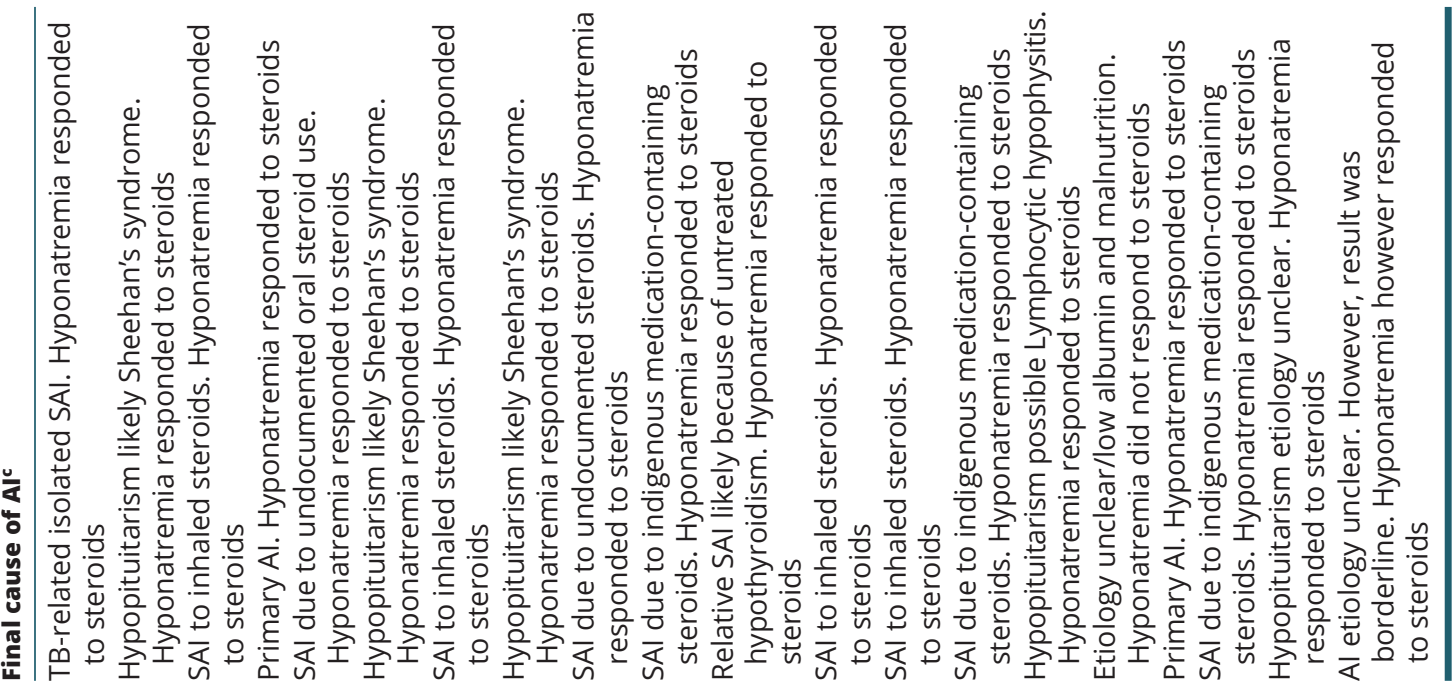

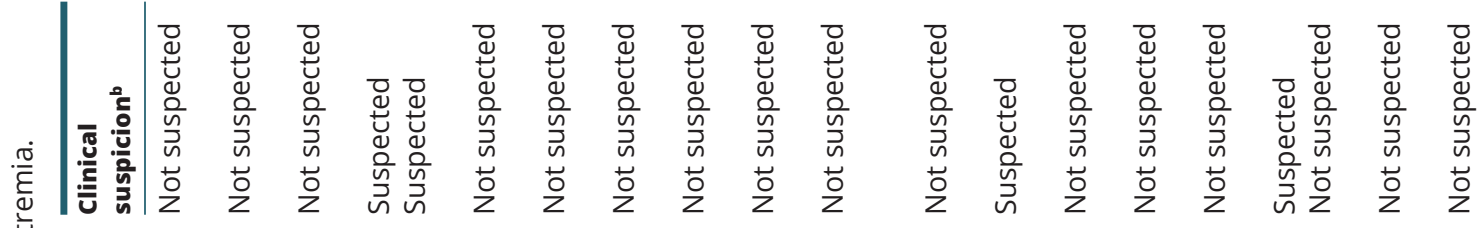

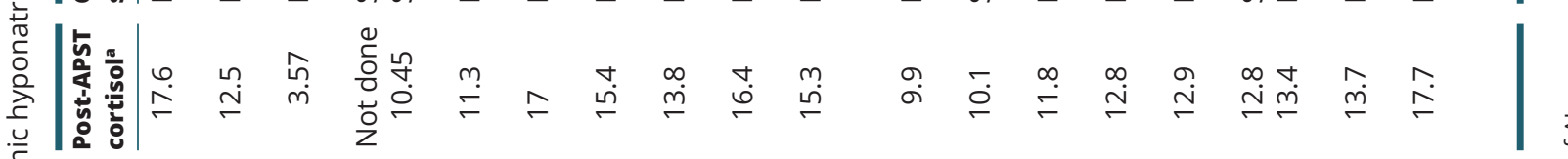

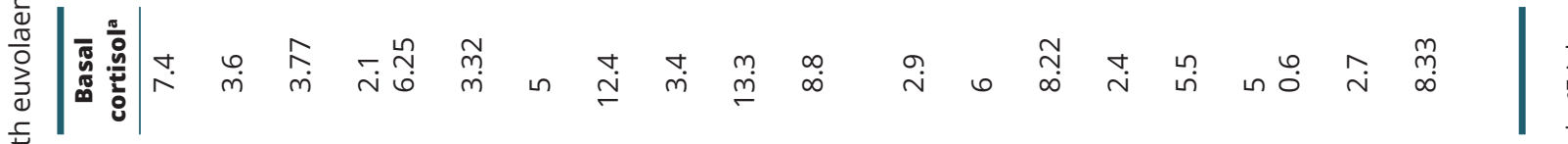

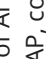

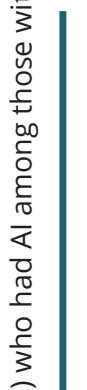

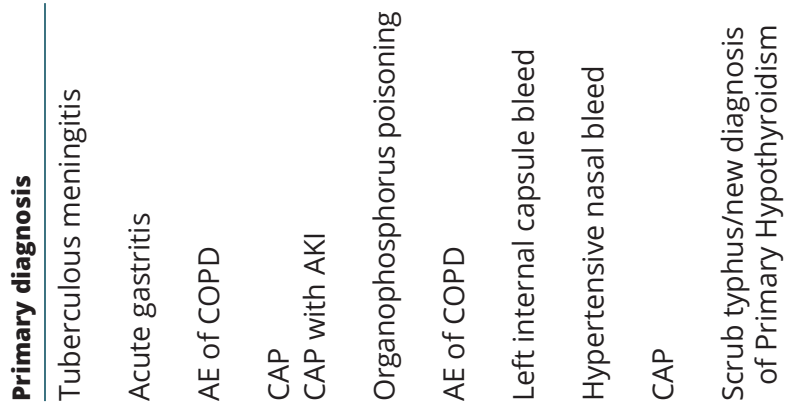

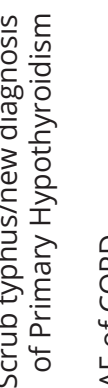

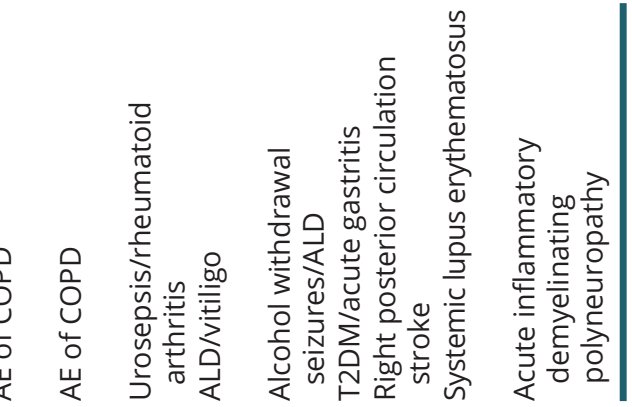
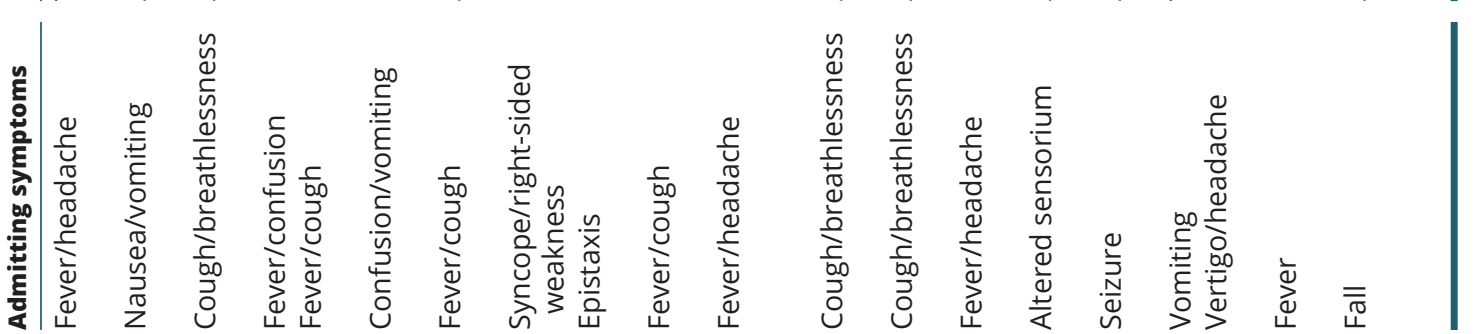

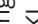

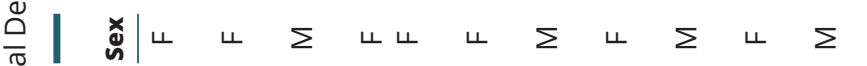

佘|

$\sum \Sigma \leftarrow \Sigma \Sigma \Sigma \Sigma$ L $\Sigma$

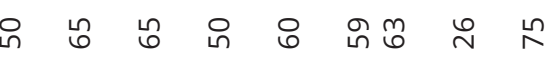

往 $\cong$

亲希

$\stackrel{n}{\square}$

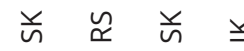

$\vec{\Sigma} \cong$

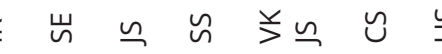


among all patients with EuVHNa). Primary AI (PAI) though does not cause of EuVHNa and is generally accompanied by some degree of dehydration was included among the study subjects as most likely these patients did not have clinically appreciable dehydration and had high urine spot sodium due to aldosterone deficiency and hence met the inclusion criteria for the study. PAI was seen in 2/20 (10 or $1.4 \%$ among all patients with EuVHNa) patients. More details are given in Fig. 1. In two patients, the etiology was unclear after work up and in retrospect at least one patient might have been erroneously labeled as having AI due to our protocol of assessment of total cortisol levels and lack of pre-specified modification of $60 \mathrm{~min}$ post-APST cut-off for AI among patients with low albumin levels. One patient had isolated SAI with tuberculous meningitis which has been previously well documented in the literature (24), and in one patient it is likely that a new diagnosis of significant untreated primary hypothyroidism led to a temporary relative AI that warranted short-term steroid replacements.

\section{Discussion}

In our study of patients with hyponatremia admitted to general medical wards in Northern India, we found that $2.5 \%(20 / 783)$ patients had biochemical evidence of AI when selected patients with EuVHNa patients underwent a stimulation test to assess HPA axis. Among patients with EuVHNa, AI was seen in 14.2\% (20/141) of patients. After exclusion of one patient with a transient relative AI due to untreated primary hypothyroidism and one patient with possible low post-APST cortisol due to low serum albumin, we still had 18/141 (12.7\%) patients who had AI with EuVHNa. This is one of the highest prevalence of AI seen among published studies. The primary driver for the high prevalence appears to be exposure to exogenous steroids in non-traditional ways including contaminated indigenous medications, over the counter use of potent steroids and high potency inhaled steroids. We had by protocol excluded patients with any prescribed use of oral or parenteral steroids up to 6 months prior to enrolment. New diagnosis of hypopituitarism was seen in $3.5 \%$ of the cohort and was in part (60\%) driven by undiagnosed longstanding post-partum pituitary necrosis that reflected poor obstetric care decades earlier in this part of the country.

In one of the largest prospective western hospitalbased study from Ireland among patients labeled to have SIAD, Cuesta and colleagues found $3.8 \%$ of patients had undiagnosed SAI. Of the 22 patients they found had SAI, 13 of those were related to exogenous steroid usage and 9 (1.5\%) because of previously unrecognized hypopituitarism. However, among the 476 patients labeled with SIAD they used a 9-h cortisol value of $>300 \mathrm{nmol} / \mathrm{L}(10.8 \mu \mathrm{g} / \mathrm{dL})$ to exclude AI and only performed 40 SSTs among patients with lower values. Additionally, they performed another eight SSTs in-patients with 9-h cortisol value of $>300 \mathrm{nmol} / \mathrm{L}$ because of a strong clinical suspicion of AI. Post-SST they used a similar cut-off of $<500 \mathrm{nmol} / \mathrm{L}(18 \mu \mathrm{g} / \mathrm{dL})$ as in our study to diagnose AI biochemically (15). Another retrospective study restricted to patients with moderate or profound hyponatremia (Serum sodium $<130 \mathrm{mmol} / \mathrm{L}$ ) found undiagnosed pituitary disease among $15 \%$ of 185 patients studied (25). Another prospective observational study involving a cohort of 298 patients with all cause profound hyponatremia (serum sodium $<125 \mathrm{mmol} / \mathrm{L}$ ) suggested that $1 \%$ of unselected patients with profound hyponatremia had AI and this worked out to $2.9 \%$ among the subgroup with EuVHNa (26). Two smaller retrospective studies determined AI in 2/59 (3.3\%) and in 3/108 (2.7\%) among patients with profound hyponatremia $(27,28)$.

Patients with secondary AI present with hyponatremia that is clinically very similar to hyponatremia seen with SIAD (29). Patients with hyponatremia because secondary AI meet all the criteria for SIAD. This is the primary reason SIAD should only be confirmed after assessment and establishment of a normal HPA axis. The primary mechanism of relative water retention leading to hyponatremia in secondary $\mathrm{AI}$ is excess $\mathrm{ADH}$ release due to a combination of stimulation of baroreceptors secondary to hypotension and the loss of steroid feedback suppression on ADH secretion (30). SIAD is generally treated by a combination of addressing the cause of SIAD and fluid restriction. However, patients with AI need glucocorticoid replacement therapy on an emergent basis and are likely to be harmed from fluid restriction. Our study suggested that the severity of hyponatremia was not indicative of the presence of $\mathrm{AI}$ and the presence of significant thyroid dysfunction should not limit the performance of ACTH stimulation testing.

The primary strengths of our study are first, the prospective use of ACTH stimulation test to assess the HPA axis among all patients with EuVHNa and suspected to have SIAD. We did not use a timed or random cortisol assessment to decide on the need for a stimulation test. This allowed us to perform the test at any time of the day upon recognition of EuVHNa, and subsequently, this led to early initiation of glucocorticoid replacement among patients with AI. Secondly, patients were recruited from general medical wards of our hospital and not from the patients in the endocrinology ward or from among

This work is licensed under a Creative Commons Attribution-NonCommercial-NoDerivatives 4.0 International License ifica com at $04 / 26 / 2023$ 11:23:41AM 


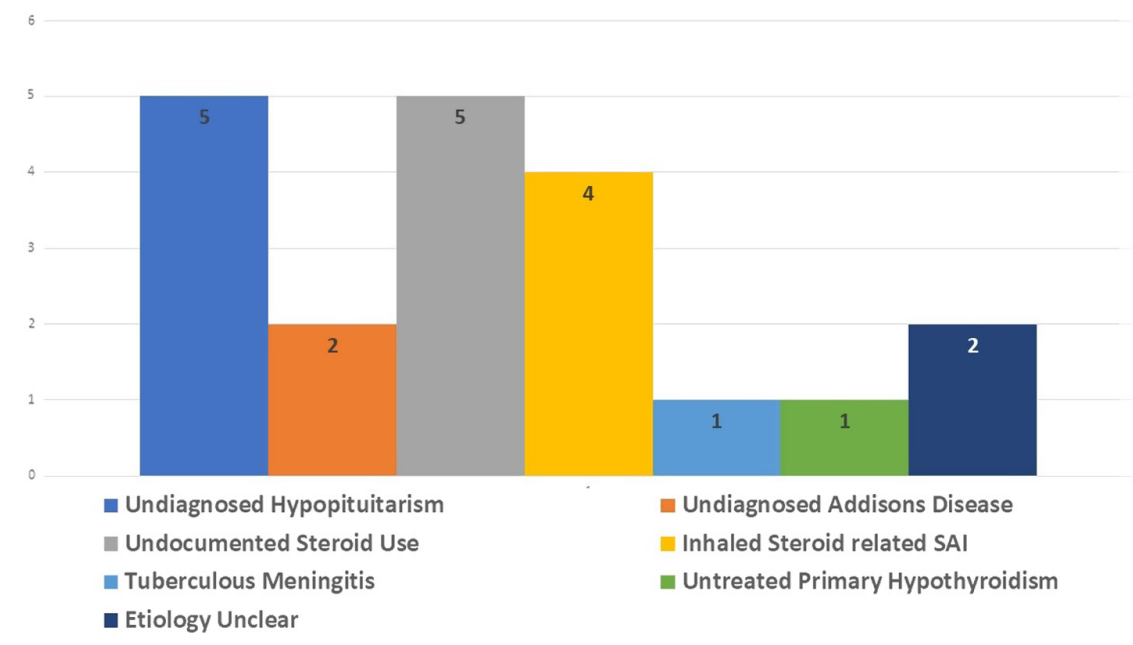

\section{Figure 1}

Bar graph detailing the various causes of adrenal insufficiency among the patients with euvolaemic hyponatremia. those referred to endocrine services reducing the bias related to endocrine referral of suspected pituitary and adrenal diseases. In only 4/20 patients, AI was clinically suspected by the treating physicians and would have led to cortisol assessments and initiation of glucocorticoid replacements.

At the time of the initiation of the study, we decided on APST rather than SST as the modality of choice for assessment of HPA axis. This was driven partly by the patchy availability of cosyntropin in the country and the cost differences between the two forms of ACTH. At that point, APST was not as well validated as it is currently and would have remained a major drawback of the study. However, over the last couple of years, publications of papers validating the use of APST have fortunately reduced some of the uncertainty related to this newer form of ACTH stimulation test $(21,22)$. Our second drawback was using the same cut-offs of $<18 \mu \mathrm{g} / \mathrm{dL}(500 \mathrm{nmol} / \mathrm{L})$ postAPST for patients with co-existing hypoalbuminemia. Since, the laboratory measures total cortisol levels and not free cortisol levels this would mean patients with low albumin and those with changes in cortisol binding globulin levels (e.g. those getting estrogen therapy) would have different total cortisol responses to APST. However, we feel this played a role in only one patient with AI in our study. Most patients with significant hypoalbuminemia would likely have edema and hence were excluded from our study. Our third drawback was using the prevalence of EuVHNa among unselected patients with hyponatremia as the basis of our sample size. We should have used the prevalence of AI among unselected patients with hyponatremia to determine the sample size. This was done primarily because the project was undertaken as a MD thesis and required to be completed in a timebound fashion to allow the first author to complete his course. The standard SST is an evaluation performed in an outpatient setting. In critically unwell patients and in patients with acute AI this is less reliable. However, we believe in-patients admitted in general medical wards this is an appropriate first screening test in patients suspected of having AI.

The other interesting finding noted in the study was the frequency of HPA axis suppression with the use of high potency inhaled steroids among patients with chronic obstructive airway disease. A recent retrospective review of SSTs was done in Birmingham; 166 SSTs were done in patients only prescribed inhaled steroids. Among these patients, 34 (20.5\%) patients failed the test and it was noted that the suppression of HPA axis was dependent on the total dose of inhaled steroids (31). Even mild hyponatremia among patients with acute exacerbation of chronic obstructive airway disease (COPD) impacted prognosis and delayed hospital discharge (32). Our findings should encourage clinicians to order evaluation of the HPA axis among patients presenting with COPD and low sodium.

In conclusion, our findings suggest that all patients with EuVHNa should undergo assessment of the HPA axis either as a single random timed sample or as a stimulation test irrespective of the degree of hyponatremia. Among hospitalized patients with EuVHNa, ACTH stimulation testing can be done at any time and once the test is performed presumptive steroids can be started in patients with high index of suspicion and among the rest once the diagnosis of AI is established. In North India, the prevalence of AI among patients with hyponatremia is 2.5\% and among selected patients with EuVHNa is likely between 12 and 14\% and makes the undertaking of an APST in all patients with EuVHNa cost-effective and clinically appropriate. 


\section{Declaration of interest}

The authors declare that there is no conflict of interest that could be perceived as prejudicing the impartiality of the research reported.

\section{Funding}

No specific funding. APST testing was funded through departmental intramural funds.

\section{Previous presentation}

The paper was presented at the Annual Meeting of the Endocrine Society in 2020 and an abstract was published: Kumar A, Ghosh M, Jacob JJ. OR25-04 Over $14 \%$ of Inpatients with Euvolemic Hyponatremia Have Undiagnosed Adrenal Insufficiency. J Endocr Soc. 2020 4(Suppl 1) OR25-04. (https://doi. org/10.1210/jendso/bvaa046.1039).

\section{Acknowledgements}

The authors would like to acknowledge the help provided by Ribka Gill (Physician Assistant) and Nisha Mathew (Endocrine Nurse) in performing the APST in the wards.

\section{References}

1 Overwyk KJ, Pfeiffer CM, Storandt RJ, Zhao L, Zhang Z, Campbell NRC, Wiltz JL, Merritt RK \& Cogswell ME. Serum sodium and potassium distribution and characteristics in the US population, national health and nutrition examination survey 2009-2016. Journal of Applied Laboratory Medicine 20216 63-78. (https://doi.org/10.1093/jalm/ jfaa127)

2 Upadhyay A, Jaber BL \& Madias NE. Incidence and prevalence of hyponatremia. American Journal of Medicine 2006119 (Supplement 1) S30-S35. (https://doi.org/10.1016/j.amjmed.2006.05.005)

3 Whelan B, Bennett K, O'Riordan D \& Silke B. Serum sodium as a risk factor for in-hospital mortality in acute unselected general medical patients. QJM 2009102 175-182. (https:/doi.org/10.1093/qjmed/ hcn165)

4 Wald R, Jaber BL, Price LL, Upadhyay A \& Madias NE. Impact of hospital-associated hyponatremia on selected outcomes. Archives of Internal Medicine 2010170 294-302. (https://doi.org/10.1001/ archinternmed.2009.513)

5 Corona G, Giuliani C, Parenti G, Norello D, Verbalis JG, Forti G, Maggi M \& Peri A. Moderate hyponatremia is associated with increased risk of mortality: evidence from a meta-analysis. PLOS ONE 20138 e80451. (https://doi.org/10.1371/journal.pone.0080451)

6 Schrier RW. Body water homeostasis: clinical disorders of urinary dilution and concentration. Journal of the American Society of Nephrology 200617 1820-1832. (https://doi.org/10.1681/ ASN.2006030240)

7 Fenske W, Störk S, Blechschmidt A, Maier SG, Morgenthaler NG \& Allolio B. Copeptin in the differential diagnosis of hyponatremia. Journal of Clinical Endocrinology and Metabolism 200994 123-129. (https://doi.org/10.1210/jc.2008-1426)

8 Berl T \& Schrier RW. Disorders of water metabolism. In Renal and Electrolyte Disorders, 5th ed., pp. 1-71. Ed. RW Schrier. Philadelphia, PA, USA: Lippincott-Raven Press, 1997.

9 Crook MA, Velauthar U, Moran L \& Griffiths W. Review of investigation and management of severe hyponatremia in a hospital population. Annals of Clinical Biochemistry 199936 158-162. (https:// doi.org/10.1177/000456329903600204)
10 Soran H, Alio Z, Pattison T, Burrows G, Cook G, Thomas M \& Kong N. Management of hyponatraemia: are we doing enough? QJM 200598 620-621. (https://doi.org/10.1093/qjmed/hci100)

11 Saeed BO, Beaumont D, Handley GH \& Weaver JU. Severe hyponatraemia: investigation and management in a district general hospital. Journal of Clinical Pathology 200255 893-896. (https://doi. org/10.1136/jcp.55.12.893)

12 Olsson K, Öhlin B \& Melander O. Epidemiology and characteristics of hyponatremia in the emergency department. European Journal of Internal Medicine 201324 110-116. (https://doi.org/10.1016/j. ejim.2012.10.014)

13 Whyte M, Down C, Miell J \& Crook M. Lack of laboratory assessment of severe hyponatraemia is associated with detrimental clinical outcomes in hospitalized patients. International Journal of Clinical Practice 200963 1451-1455. (https://doi.org/10.1111/j.17421241.2009.02037.x)

14 Tzoulis P \& Bouloux PM. Inpatient hyponatraemia: adequacy of investigation and prevalence of endocrine causes. Clinical Medicine 201515 20-24. (https://doi.org/10.7861/clinmedicine.15-1-20)

15 Cuesta M, Garrahy A, Slattery D, Gupta S, Hannon AM, Forde H, McGurren K, Sherlock M, Tormey W \& Thompson CJ. The contribution of undiagnosed adrenal insufficiency to euvolaemic hyponatraemia: results of a large prospective single-centre study. Clinical Endocrinology 201685 836-844. (https://doi.org/10.1111/ cen.13128)

16 Masih S, Cynthia Stephen S, Joy Armstrong L \& Finny P. Use and misuse of glucocorticoids in the community of Raxaul Block, North Bihar. Tropical Doctor 201545 68-72. (https://doi. org/10.1177/0049475514567756)

17 Zargar AH, Singh B, Laway BA, Masoodi SR, Wani AI \& Bashir MI. Epidemiologic aspects of postpartum pituitary hypofunction (Sheehan's syndrome). Fertility and Sterility 200584 523-528. (https:// doi.org/10.1016/j.fertnstert.2005.02.022)

18 Bornstein SR, Allolio B, Arlt W, Barthel A, Don-Wauchope A, Hammer GD, Husebye ES, Merke DP, Murad MH, Stratakis CA, et al. Diagnosis and treatment of primary adrenal insufficiency: an Endocrine Society clinical practice guideline. Journal of Clinical Endocrinology and Metabolism 2016101 364-389. (https://doi. org/10.1210/jc.2015-1710)

19 Ospina NS, Al Nofal A, Bancos I, Javed A, Benkhadra K, Kapoor E, Lteif AN, Natt N \& Murad MH. ACTH stimulation tests for the diagnosis of adrenal insufficiency: systematic review and metaanalysis. Journal of Clinical Endocrinology and Metabolism 2016101 427-434. (https://doi.org/10.1210/jc.2015-1700)

20 Gundgurthi A, Garg MK, Dutta MK \& Pakhetra R. Intramuscular ACTH stimulation test for assessment of adrenal function. Journal of the Association of Physicians of India 201361 320-324.

21 Wagmode NB, Mathew V, Bantwal G, Ayyar V, George B, Patanjali CP $\&$ Michael J. It is time to carpe diem with porcine ACTH - a comparison of porcine sequence corticotropin to tetracosactide hexaacetate in testing the hypothalamic pituitary adrenal axis in healthy individuals. Indian Journal of Endocrinology and Metabolism 201822 636-640. (https://doi.org/10.4103/ijem.IJEM_114_18)

22 Nair A, Jayakumari C, George GS, Jabbar PK, Das DV, Jessy SJ \& Aneesh TS. Long-acting porcine sequence ACTH in the diagnosis of adrenal insufficiency. European Journal of Endocrinology 2019181 639-645. (https://doi.org/10.1530/EJE-19-0558)

23 Chatterjee N, Sengupta N, Das C, Chowdhuri AR, Basu AK \& Pal SK. A descriptive study of hyponatremia in a tertiary care hospital of Eastern India. Indian Journal of Endocrinology and Metabolism 201216 288-291. (https://doi.org/10.4103/2230-8210.93757)

24 Jacob JJ \& Paul PAM. Infections in endocrinology: tuberculosis. In Endotext. Eds KR Feingold, B Anawalt, A Boyce, et al. South Dartmouth, MA, USA: MDText.com, Inc., 2021. (available at: https://www.ncbi. nlm.nih.gov/books/NBK568566/) https://ec.bioscientifica.com https://doi.org/10.1530/EC-21-0500 (c) 2021 The authors Published by Bioscientifica Ltd
This work is licensed under a Creative Commons Attribution-NonCommercial-NoDerivatives 4.0 elnternational License.ifica com at $04 / 26 / 2023$ 11:23:41AM 
25 Diederich S, Franzen NF, Bähr V \& Oelkers W. Severe hyponatremia due to hypopituitarism with adrenal insufficiency: report on 28 cases. European Journal of Endocrinology 2003148 609-617. (https://doi. org/10.1530/eje.0.1480609)

26 Nigro N, Winzeler B, Suter-Widmer I, Schuetz P, Arici B, Bally M, Blum C, Bingisser R, Bock A, Huber A, et al. Symptoms and characteristics of individuals with profound hyponatremia: a prospective multicenter observational study. Journal of the American Geriatrics Society 201563 470-475. (https://doi.org/10.1111/jgs.13325)

27 Laloë PA, Wong A \& Murphy MJ. Results of measurement of urine osmolality and sodium in the evaluation of severe hyponatraemia. Journal of Clinical Pathology 200356 883-884. (https://doi.org/10.1136/ jcp.56.11.883-a)

28 Clayton JA, Le Jeune IR \& Hall IP. Severe hyponatraemia in medical in-patients: aetiology, assessment and outcome. QJM 200699 505-511. (https://doi.org/10.1093/qjmed/hcl071)

29 Oelkers W. Hyponatremia and inappropriate secretion of vasopressin (antidiuretic hormone) in patients with hypopituitarism. New England
Journal of Medicine 1989321 492-496. (https://doi.org/10.1056/ NEJM198908243210802)

30 Kamoi K, Tamura T, Tanaka K, Ishibashi M \& Yamaji T. Hyponatremia and osmoregulation of thirst and vasopressin secretion in patients with adrenal insufficiency. Journal of Clinical Endocrinology and Metabolism 199377 1584-1588. (https://doi.org/10.1210/ jcem.77.6.8263145)

31 Woods CP, Argese N, Chapman M, Boot C, Webster R, Dabhi V, Grossman AB, Toogood AA, Arlt W, Stewart PM, et al. Adrenal suppression in patients taking inhaled glucocorticoids is highly prevalent and management can be guided by morning cortisol. European Journal of Endocrinology 2015173 633-642. (https://doi. org/10.1530/EJE-15-0608)

32 García-Sanz MT, Martínez-Gestoso S, Calvo-Álvarez U, DovalOubiña L, Camba-Matos S, Rábade-Castedo C, Rodríguez-García C \& González-Barcala FJ. Impact of hyponatremia on COPD exacerbation prognosis. Journal of Clinical Medicine 20209 503. (https://doi. org/10.3390/jcm9020503)

Received in final form 29 October 2021

Accepted 17 November 2021

Accepted Manuscript published online 17 November 2021 (c) 2021 The authors Published by Bioscientifica Ltd
This work is licensed under a Creative Commons Attribution-NonCommercial-NoDerivatives 4.0 Internationab dicense ifica. com at 04/26/2023 11:23:41AM 